\title{
ALCANCES Y LIMITACIONES DEL MÉTODO CUANTITATIVO PARA TRABAJAR CON PUEBLOS INDÍGENAS. APORTES INTERDISCIPLINARIOS DESDE LAS CIENCIAS SOCIALES
}

\author{
Autoras: ${ }^{1}$ \\ Julia COLLA ${ }^{2}$ \\ Macarena Del Pilar MANZANELLI ${ }^{3}$ \\ Rocío M. MÍGUEZ PALACIO ${ }^{4}$
}

\section{Resumen:}

Este artículo analiza los alcances del método cuantitativo para abordar los pueblos indígenas en Argentina. Desde la construcción político-ideológica de la etnicidad se describe la manera en que el Estado elaboró información censal sobre estas poblaciones en distintos momentos históricos y se detallan una serie de producciones estadísticas generadas por instituciones académicas, ONG's o por los propios pueblos indígenas. La apuesta apunta a una mirada interdisciplinaria sobre las potencialidades del método para visibilizar distintos fenómenos sociales y, también, se atiende a los recaudos necesarios para abordar la diversidad cultural y socioeconómica.

Palabras clave: estadística-pueblos originarios-interdisciplina-etnicidad

\footnotetext{
${ }^{1}$ El orden de las autoras es alfabético, por tanto no implica jerarquía.

2 Instituto de Humanidades y Ciencias Sociales del Litoral (IHUCSO Litoral), Universidad Nacional del Litoral y Consejo Nacional de Investigaciones Científicas y Técnicas (UNL-CONICET), Paraje El Pozo, s/n, Santa Fe. julialcolla@gmail.com

${ }^{3}$ Universidad Nacional de La Matanza. Buenos Aires; Argentina.

Consejo Nacional de Investigaciones Científicas y Técnicas (CONICET), Departamento de Derecho y Ciencia Política - Universidad Nacional de La Matanza (UNLaM), Florencio Varela 1903, San Justo, Buenos Aires. mdpmanzanelli@gmail.com

${ }^{4}$ Universidad de Buenos Aires. Ciudad Autónoma de Buenos Aires. Buenos Aires; Argentina.

Consejo Nacional de Investigaciones Científicas y Técnicas (CONICET), Instituto de Ciencias Antropológicas (ICA), Facultad de Filosofía y Letras (FFyL), Universidad de Buenos Aires (UBA). Puan 480, Ciudad Autónoma de Buenos Aires. .rmmiguezpalacio@gmail.com
} 


\title{
Résumé:
}

Cet article analyse la portée de la méthode quantitative pour traiter des peuples indigènes en Argentine. À partir de la construction politico-idéologique de l'ethnicité, il décrit la manière dont l'État a élaboré des informations de recensement sur ces populations à différents moments de l'histoire et détaille une série de productions statistiques générées par des institutions académiques, des ONG ou les peuples indigènes eux-mêmes. L'objectif est de jeter un regard interdisciplinaire sur le potentiel de la méthode pour rendre visibles différents phénomènes sociaux, et aussi d'aborder les précautions nécessaires pour faire face à la diversité culturelle et socio-économique.

Mots-clés: statistiques-peuples indigènes-interdiscipline-ethnicité

\begin{abstract}
:
This article analyses the scope of the quantitative method for dealing with indigenous peoples in Argentina. From the political-ideological construction of ethnicity, it describes the way in which the state has elaborated census information on these populations at different historical moments and details a series of statistical productions generated by academic institutions, ONG's or indigenous peoples themselves. The aim is to take an interdisciplinary look at the potential of the method to make different social phenomena visible, and also to address the necessary precautions to deal with cultural and socioeconomic diversity.
\end{abstract}

Keywords: statistics-indigenous peoples-interdiscipline-ethnicity

\section{Introducción}

Este artículo reflexiona sobre el tratamiento y la forma de clasificar y cuantificar la diversidad cultural de los pueblos indígenas en Argentina. En especial, se analizan los alcances y las limitaciones de las técnicas que producen información estadística (censos, encuestas, relevamientos) generadas por instituciones académicas, organismos estatales y no gubernamentales (ONG's). El interés reside en mostrar tanto los alcances analíticos que posee la estadística para visibilizar determinados fenómenos sociales como las limitaciones que presenta en el tratamiento y construcción de la etnicidad al pretender cuantificar realidades diversas.

Al respecto, tomamos al concepto de etnicidad como la expresión política de la identidad étnica, cuestión que entendemos como central por la manera en que las personas indígenas se autodefinen o son consideradas por otros (Bonfil Batalla, 1972; Bartolomé, 1997; Vázquez, 2000; 2018). En este artículo trabajamos dicho concepto desde dos aspectos diferentes, y a la vez, complementarios. Por un lado, la construcción política-ideológica realizada por el Estado argentino (y sus distintas agencias) desde su relación de poder basada en el dominio/sometimiento- hacia los pueblos originarios. Esto es importante para comprender los procesos administrativos-burocráticos implementados en cada momento histórico para cuantificar la población indígena -sobre todo en los Censos Nacionales de Población- enmarcados en los llamados "asuntos indígenas" (Lenton, 2010; Balazote, 2015; Barrientos, 2015). Por el otro, la identidad política indígena que se manifiesta en las distintas estrategias de resistencia que llevan a cabo estas poblaciones. Dentro de ellas, reconocemos las disputas en el campo ideológico para revertir las lógicas 
clasificatorias y la búsqueda de variables que contengan propiedades atribuibles a la diversidad cultural y socioeconómica de los pueblos indígenas. Como veremos, esta disyuntiva se expresó durante la década de 1990 en la movilización indígena por la incorporación de la variable de autorreconocimiento en los relevamientos oficiales, como así también, en la elaboración y difusión por parte de ONG's y diversas instituciones, de datos cuantitativos referidos a conflictos territoriales, socioambientales y legales que afectan a los pueblos indígenas. Vale destacar que la información que se produce en uno u otro espacio, con acuerdos y tensiones, son herramientas disponibles que dependen de la agencia indígena para su uso o utilidad es pos del cumplimiento de sus derechos.

A partir de esta doble forma de entender a la etnicidad, podemos dar cuenta que en nuestro país, con similitudes y diferencias respecto del resto de Latinoamérica, la cuestión indígena estuvo históricamente sustentada sobre procesos de obliteración e invisibilización. Esto produjo una matriz histórica, territorial y cultural unitaria de la identidad nacional que ocultó la existencia de estas poblaciones y las asimiló con las capas más bajas de la sociedad (Trinchero, 2000; Lenton, 2010; Balazote, 2015). La administración y las políticas públicas fueron impartiendo distintas consideraciones con estos pueblos y las estadísticas públicas acompañaron estos procesos, con distintas maneras de cuantificarlos y abordarlos en cada momento histórico.

No obstante, desde mediados de la década de 1980 se generó un proceso de reemergencia y visibilidad indígena, producto de la lucha etnopolítica de estas poblaciones, su incorporación dentro de las órbitas estatales y el surgimiento de novedosos marcos legales específicos. Las estadísticas públicas acompañaron este proceso. El Estado comenzó a construir nuevas variables como gestor de operativos estadísticos -cantidad de nacimientos, defunciones, composición familiar, entre otras-, que permitieron cartografiar y caracterizar a la población indígena y mostrar ciertas regularidades (Barrientos, 2015). Este interés por identificar y contabilizar a las que se denominaron "nuevas realidades sociales" se plasmó, por caso, en el Censo poblacional del año 2001, en encuestas complementarias a pueblos indígenas donde se dispusieron esfuerzos por dar cuenta del proceso de reconocimiento y disponer de información confiable, oportuna y pertinente sobre la población originaria.

Dichos activismos y participación política de los pueblos indígenas, presentaron grandes desafíos. El Estado estableció criterios para oficializar la pertenencia de personas a los pueblos indígenas reconocidos a través del Registro Nacional de Comunidades Indígenas -Re.Na.Ci- (Ley 23.302). Además, la estadística pública intentó dar cuenta de los colectivos heterogéneos -pautas culturales, modos de vida, organización socioproductiva, política, entre otros aspectos- a través de la elaboración y selección de variables e indicadores para reflejar dicha complejidad (Del Popolo, 2008; CEPAL; 2009). No obstante, como veremos, estos criterios normalmente no fueron tenidos en cuenta en los operativos censales y muchas veces fueron considerados como no fiables por parte de la comunidad académica.

En línea y tensión con este proceso, diversos organismos no gubernamentales nacionales e internacionales (Fundapaz, Amnistía Internacional, Equipo Nacional de Pastoral Aborígen -ENDEPA-, Red Agroforestal Chaco Argentina -REDAF-, entre otros) e instituciones académicas abocadas a diversas disciplinas produjeron investigaciones y 
elaboraron datos estadísticos e informes propios. Muchos de ellos surgieron a partir de demandas de los mismos pueblos indígenas que frente a determinados conflictos no contaban con información fehaciente y disponible. Estos materiales se tradujeron en mapas colaborativos, cartografías de actualización periódica, informes y artículos académicos de difusión pública. Allí, se evidenció un esfuerzo por sortear las dificultades ontológicas y metodológicas de los dispositivos censales oficiales y un interés por abordar de manera integral e interdisciplinaria la diversidad cultural y socioeconómica de los pueblos. Además, en diversas producciones académicas se introdujeron los enfoques interespistémicos que permitieron pensar la producción relacional del conocimiento y la circularidad dialéctica de la subjetividad/objetividad (Trinchero y Petz, 2014; Maidana, 2019: 256; Manzano, 2019).

De manera que en este artículo se mencionan las producciones oficiales -esto es, censos y cuestionarios estatales-, académicas y de organismos no estatales que proporcionaron información estadística para el abordaje de esta doble construcción de la etnicidad. De esta forma, se tienen en cuenta, por un lado, las limitaciones que proporciona el método de asociación para el abordaje de la diversidad cultural. Y por el otro, se apuesta a pensar la interdisciplinariedad y la interculturalidad como elementos sumamente enriquecedores para construir datos que permitan conocer la diversidad cultural y visibilizar los distintos tipos de conflictos y luchas etnopolíticas que se desarrollan en los territorios.

En correspondencia con este planteo, la organización del trabajo consiste, en primer lugar, en el desarrollo del marco teórico donde se enfatiza en la noción de etnicidad y la relación entre Estado y pueblos originarios basada en procesos de sometimiento, explotación y subalternización. En segundo lugar, se analiza, por un lado, el abordaje de la cuestión indígena en los distintos censos nacionales que incluyeron la variable indígena, estableciendo un cambio de abordaje a partir del Censo Nacional de Población, Hogares y Viviendas 2001 y los nuevos marcos regulatorios de derechos específicos. Por otro lado, se describen distintas producciones de datos estadísticos realizadas por ONG's, instituciones académicas o por los propios pueblos indígenas sobre conflictos territoriales, socioambientales y legales. En tercer lugar, identificamos las ventajas y limitaciones que ofrece el método cuantitativo en la producción de estadísticas para el abordaje de la diversidad cultural y socioeconómica, y se alude a una serie de limitaciones difundidas en el método cuantitativo en Ciencias Sociales. En cuarto orden, y ante estas consideraciones, presentamos como alternativa el abordaje interdisciplinario e integral que permita superar las dificultades mencionadas y habilita nuevas formas de construcción de conocimiento y, por lo tanto, de las categorías empleadas en los instrumentos estadísticos. Finalmente, se presentan las conclusiones a las que se arribó luego del análisis realizado.

\subsection{La etnicidad en sus dos frentes de construcción política. La relación entre el Estado y los pueblos originarios}

El concepto de identidad étnica se refiere a una identidad colectiva y es multidimensional (Vázquez, 2000). La etnicidad referencia los rasgos socioculturales en la construcción político ideológica de dicha identificación. Según Bartolomé (2006) esta es algo más que interacción de grupos diferenciados e incluso sostiene que es una identidad en "sí misma", como una "conciencia para sí”, resultado de una acción que estructura conductas políticas 
en un contexto de relaciones socioculturales de dominio-sometimiento. $\mathrm{O}$ en otras palabras, consiste en que la posibilidad de que una identidad se construya y manifieste depende del balance de fuerzas existentes en el "campo de poder" (Bourdieu y Wacquant, 2005).

En esta línea, Cardoso de Oliveira (1992) sostiene que la etnicidad alude a las modalidades de interacción entre grupos sociales diferenciados en un contexto social determinado en el que, mientras uno es mayoritario, los otros conforman una minoría. Coincidimos con Vázquez en que "es precisamente esta relación de desigualdad y no de pura asimetría la que interesa puesto que alude a dos aspectos diferentes, y a la vez, complementarios de la etnicidad" (2000:68).

Al respecto presenta dos frentes de construcción de la misma. El primero es la construcción política que producen tanto los organismos del Estado (a nivel municipal, provincial y nacional), las colectividades étnicas mayoritarias en una sociedad civil como las expresiones elaboradas por los medios masivos de comunicación. El segundo consiste en las estrategias etnopolíticas desarrolladas por las organizaciones de pueblos originarios, quienes emplean los requisitos legales disponibles, apoyados por organizaciones no gubernamentales, organismos internacionales y diversas instituciones que contribuyen a garantizar los derechos humanos de estos pueblos.

En efecto, si nos posicionamos en el primer aspecto, resulta necesario mencionar que desde su surgimiento y construcción, en el siglo XIX, el Estado argentino manifestó interés por cuantificar a las poblaciones preexistentes que habían sido ya sometidas -bajo diferentes mecanismos- desde el período de conquista e invasión de América ${ }^{5}$. En gran medida esto se debía a la necesidad de, por un lado, administrar las fronteras internas para conocer la disponibilidad de mano de obra indígena (sobre todo en los territorios del norte donde las poblaciones indígenas eran sometidas y explotadas en el trabajo asalariado), por otro lado, avanzar sobre territorios que habían quedado fuera del dominio del imperio español por medio de las llamadas "campañas del desierto" sobre las Regiones Patagónica y Chaqueña. Además, respondió a controlar las fronteras externas (los denominados territorios libres para indígenas) previniendo posibles ataques a los fortines militares. Junto con esto el Estado elaboró una "construcción simbólica del indígena" que estuvo fundamentada por un discurso dominante basado en la antinomia "civilización" y "barbarie" sobre el que se planteó una matriz histórica, territorial y cultural unitaria de la

\footnotetext{
${ }^{5}$ Es importante aclarar que si bien partimos de la conformación del Estado-nacional argentino, el proceso de dominación, subalternización y explotación simbólica y material hacia los pueblos originarios se inició con la conquista de América (Mignolo, 2007; Quijano, 2014). Entre los diversos acontecimientos, se destacan una variedad de estrategias materiales y simbólicas -traslados forzosos o extrañamientos de las poblaciones indígenas, encomiendas, la creación de reducciones y Pueblos de Indios- empleadas por la Corona Española, junto con las autoridades criollas, para lograr su dominación. Luego, se llevó a cabo un proceso de modernización económica y administrativa en las colonias, a través de las Reformas Borbónicas y con la creación del Virreinato del Río de La Plata. Dichas reformas instauraron un estilo de gobierno de tipo economicista para ampliar los beneficios de la metrópoli, introdujo modificaciones en en las categorizaciones y en las figuras de Pueblos de Indios. Asimismo, condujo a nuevas formas de tenencia de la tierra bajo la propiedad privada, consolidadas años más tarde durante el período de conformación del Estado-nación argentino, las cuales resquebrajaron la condición corporativa-comunitaria de las tierras (Lorandi, 1988; Boixadós, 2012; Manzanelli, 2021b).
} 
identidad nacional (Balazote, 2015). De esta manera, los pueblos originarios fueron clasificados racial y étnicamente -en función de rasgos fenotípicos y culturales- como "otros internos" incorporados asimétricamente a la estructura económica política nacional (Carrasco, 2000; Briones, 2008; Manzanelli, 2021).

Producto de estos procesos de invisibilización, negación y asimilación, se generó un fuerte arraigo en el sentido común de la idea de que Argentina es un país "sin indios" (Bartolomé, 2003, Trinchero, 2010). Este mito acompañaba otro, que aludía a que "los argentinos venimos de los barcos", haciendo referencia a la inmigración europea a entre finales del siglo XIX y principios del siglo XX, produciendo un distintanciamiendo social respecto de los pueblos indígenas en la población argentina (Ratier, 2010; Míguez Palacio, 2021). Así, estas imágenes expresaron relaciones sociales que fueron sustento de una identidad nacional construida desde la experiencia migrante e invisibilizaron la identidad étnica y los modos de vida de los pueblos originarios sobrevivientes al genocidio. De aquí surgieron las narrativas basadas en "identidades políticamente estigmatizadas" las cuales enfatizaron la belicosidad, el arcaísmo y el salvajismo de los nativos y generaron extrañamiento social frente a la supuesta "identidad argentina" (Trinchero, 2007). De esta manera, el prejuicio social se consolidó como "estigma" que, en la actualidad, estereotipa lo étnico y percibe a los indígenas como grupos sociales minoritarios y aislados. Esto también funciona como espacio propicio para la expansión de los procesos de acumulación económica, que refuncionaliza la captación de mano de obra indígena, y la valorización y uso del suelo.

Con relación al segundo aspecto de la etnicidad, las acciones políticas de la identidad han sido desarrolladas por los distintos grupos étnicos involucrados en la problemática de la territorialidad, en tanto espacio de producción y reproducción de la vida social (Vázquez, 2000). Particularmente nos interesa aquí detenernos en las estrategías etnopolíticas focalizadas en el campo ideológico (y material) que constituyen un conjunto amplio de acciones para revertir las lógicas clasificatorias impuestas en la relación de dominio/sometimiento con el Estado y el resto de los actores sociales. Con ellas se espera construir marcos conceptuales y clasificatorios que permitan visibilizar y cuantificar la diversidad cultural de los distintos pueblos y acceder a derechos. De manera que la participación indígena para la construcción de los dispositivos censales, la importancia política que otorgan los informes y relevamientos técnicos sobre la cantidad de conflictos territoriales, socioambientales, legales -entre otros- y las propias producciones de las comunidades para contar con datos estadísticos, constituyen herramientas que son parte de la resistencia étnica. Es decir, de las distintas respuestas encarnadas en reivindicaciones y propuestas indígenas reflejadas en actitudes, valores y pautas de conducta que los miembros de los pueblos originarios construyen (en el ámbito individual y colectivo) como réplicas a las distintas expresiones concretas de coerción a las que son sometidos (Vázquez, 2000; Bigot, Rodríguez, y Vázquez, 2001).

El abordaje planteado hasta aquí permite trazar un escenario analítico para reflexionar sobre el tratamiento y la forma de clasificar y cuantificar la diversidad cultural de los pueblos indígenas. En esta línea, en los siguientes apartados veremos las distintas construcciones de la variable indígena utilizada en diversos instrumentos estadísticos. Vale destacar que la información que se produce en los distintos espacios, con acuerdos 
y tensiones, son herramientas disponibles que dependen de la agencia indígena para su uso o utilidad es pos del cumplimiento de sus derechos.

\subsection{El tratamiento estadístico de la cuestión indígena: los censos nacionales de población}

Las estadísticas oficiales presentan datos numéricos sobre la población auto reconocida como indígena en Argentina, así como también tienen el efecto de recrear y sostener ciertos imaginarios nacionales, cartografiar a la población, sus relaciones de poder e intervenir en ellas. El Estado-nación ha sido el gestor de esos operativos estadísticos, al concentrar la información, su tratamiento y distribución (Bourdieu, 1993). Para ello, selecciona, define y clasifica a la variable indígena (Barrientos, 2015).

En un breve repaso sobre las tradiciones censales que tuvo Argentina, encontramos cinco censos donde la variable indígena fue incluida: el primer Censo Indígena Nacional (en adelante CIN) $-1966-{ }^{6}$, el Censo Provincial del Aborigen de Formosa (en adelante CAF) -1970- el Censo Aborigen Provincial realizado en la provincia de Salta (en adelante CAP) -1984-, Censo Nacional del año 2001 con la Encuesta Complementaria 2004-2005 (en adelante ECPI) y el Cuestionario Ampliado incluido en el último Censo Nacional del año $2010^{7}$.

Tanto el CIN, el CAF - y el CAP mantuvieron en común la lógica de la aculturación mediante el uso de criterios de autenticidad y "pureza" para identificar y cuantificar a la población originaria. Además, subyacían calificaciones de los pueblos originarios como objetos pasivos.

No obstante, también encontramos algunas particularidades. El CIN se inspiró en las teorías estructuralistas latinoamericanas y de la modernización. Los pueblos originarios fueron concebidos en función de la falta de integración a la comunidad nacional y moderna, de forma tal que se sostenía que era necesario identificar la personalidad social del indígena e inducir procesos de aculturación para mejorar el desarrollo social, económico, sanitario y educativo (Iñigo Carrera, 2014; Barrientos, 2015). Resulta importante destacar el rol de la academia en la construcción de estas definiciones y variables al participar en la Comisión del $\mathrm{CIN}^{8}$. Las categorías y definiciones empleadas

\footnotetext{
${ }^{6}$ El CIN se realizó durante el gobierno constitucional de Arturo Illia y el gobierno de facto de Onganía (1968).

7 Anteriormente, los censos nacionales de población de fines del siglo XIX y comienzos del XX, como el primer Censo Nacional de Población -1869-, el Segundo Censo -1898- y en Tercer Censo Nacional -1914se caracterizaron por un proceso de invisibilización jurídico-política de la población indígena plasmadas en criterios de autenticidad y "pureza" -nociones de "indio naturaleza", "indio estatua", indómito o reliquiavistos como amenaza a la conquista de los territorios nacionales (mal denominada Campaña al Desierto (1879) y del Chaco (1884). Por su parte, en el segundo Censo predominó la categoría de nacionalidad como variable para cuantificar a los extranjeros, y se reforzó la idea de indio ausente, en "desaparición", asimilación e "interiorización de las líneas de color" a la civilización. En el tercero, la población originaria fue contabilizada en función del número de lanzas (Trinchero, 2010; Gordillo y Hirsch, 2010; Barrientos, 2015; INDEC, 2015a).

8 El paradigma imperante para abordar el "problema indígena" se encontraba estrechamente relacionado con las líneas principales del indigenismo oficial mexicano y por la naciente Antropología Social. El indigenismo de los años '60 apostó a la integración del indio a las sociedades nacionales a través de su desarrollo; lo cual da cuenta que la concepción de los pueblos originarios era de "subdesarrollados" y carentes, tal como se puede evidenciar en el Convenio 107 de la OIT -1960-. El conocimiento de la realidad
} 
de la antropología básica eran esencialistas como se mostraba con la asociación entre identidad con territorio de carácter rural generando una cartografía indígena ruralizada; también eran culturalistas al considerar a la población que convivía en grupo o comunidad en base a la conciencia de pertenencia -actual o histórica- a un grupo prehispánico de forma colectiva (Iñigo Carrera, 2014). Asimismo, subyacía la noción de autenticidad mediante diacríticos de "indianidad-pureza racial" y uso de la lengua originaria (Lenton, 2010; Iñigo Carrera, 2014; Barrientos, 2015).

En el caso del CAF, además de mantener un tratamiento hacia la población de forma estereotipada y asociado a lo primitivo, también introdujo la categoría de religión sustentada en valores de la moral occidental y cristiana con derivaciones hacia las políticas públicas. Por su parte en el diseño e implementación del CAP se buscó dar cuenta del cambio cultural mediante estudios comparativos de un mismo grupo étnico, al relevar sus distintas etapas de incorporación de hábitos y elementos culturales, en reemplazo o no de las formas tradicionales. Los criterios de identificación de la población indígena se basaron tanto en pautas consideradas objetivas -diferencias de las agrupaciones por sus costumbres, estructuras socioculturales y/o lingüísticas y economías de subsistencia- como en pautas entendidas como subjetivas -expresión consciente del sentido de pertenencia o identidad con un grupo étnico determinado-. El pretendido criterio objetivo para determinar un cambio cultural resulta insuficiente al reducir la diversidad de poblaciones originarias a una lógica de casilleros, como si fuesen unidades discretas que se auto perpetúan como un todo autosuficiente y autosustentable, de forma estática y descontextualizada que no contempla la historicidad. Además, se enfatizó en descripciones de pérdida de las tradiciones y el contacto con las zonas urbanas, siendo consistentes con los objetivos de los procesos de aculturación (Barrientos, 2015).

En el año 1998, en el marco de un contexto de revitalización de activismos de pueblos originarios y de reconocimiento formal-jurídico a las diversidades y de organismos internacionales que emitieron declaraciones sobre los pueblos originarios ${ }^{9}$, se sancionó la

indígena, mediante registros estadísticos, ya había constituido una de las recomendaciones para una política indigenista de los países latinoamericanos producida en el marco del Primer Congreso Indigenista Interamericano realizado en la ciudad de Pátzcuaro (México) en el año 1940. Asimismo, se consideraron, para identificar a la población originaria, recomendaciones emanadas de los Congresos Indigenistas Interamericanos como el de 1954 en la ciudad de La Paz (Bolivia), donde se señalaba que resultaba conveniente uniformar los criterios -linguiísticos, culturales y sociales- para identificar y relevar a los "indios" (Lenton, 2010; Iñigo Carrera, 2014).

9 Por ejemplo, la Convención Internacional sobre la Eliminación de todas las Formas de Discriminación Racial (CERD), la Declaración y Programa de Acción de Durban, la Conferencia Internacional sobre la Población y el Desarrollo (CIPD, El Cairo, 1994), la Conferencia Mundial contra el Racismo, la Discriminación Racial, la Xenofobia, y las Formas Conexas de Intolerancia (CMR, Durban, 2001), la Declaración del Milenio (New York, 2000), recomendaron a los Estados tomar las medidas para recabar datos desagregados según el origen étnico y racial. Asimismo, se han sumado normativas internacionales como el Convenio 169 de la OIT y la Declaración de las Naciones Unidas sobre los Derechos de los Pueblos Indígenas que establece, en relación a la información, la necesidad de generar visibilidad estadística. Por su parte desde la CEPAL, el CELADE -División de Población, Centro Latinoamericano y Caribeño de Demografía- desarrolló actividades respecto a los pueblos indígenas y afrodescendientes de América Latina, sobre todo en respuesta a las nuevas demandas de información y siguiendo, además, las recomendaciones emanadas del Foro Permanente para las Cuestiones Indígenas de las Naciones Unidas. Los asuntos de población que aborda el CELADE consideran la diversidad cultural de la región y, en particular, incorpora la perspectiva de dichos grupos sociales (CEPAL, 2009; Iñigo Carrera, 2014). 
Ley 24.956 denominada "Censo Aborigen" para incorporar, por primera vez en un Censo Nacional, la medición de población indígena a partir del criterio de autorreconocimiento u autopercepción. Como forma de análisis de las condiciones de vida de la población indígena, residente tanto en ámbitos rurales como urbanos. Dicha pregunta se conformó en, por un lado, indagar acerca de la pertenencia a un pueblo indígena con opciones de respuesta "sí" o "no". En caso de que la respuesta fuese afirmativa, se interrogaba sobre el pueblo de pertenencia ${ }^{10}$. Entre las dificultades se encontraron la falta de participación de pueblos originarios en el proceso acerca de cómo se implementaría el Censo 2001. Ante esta situación, las organizaciones de pueblos originarios exigieron suspender la realización del mismo, al denunciar que no se respetaban los mecanismos de consulta previstos en el art. 6 del Convenio 169 de la OIT; el art. 75, inc. 17 de la Constitución Nacional y el art. $1^{\circ}$ de la Ley 23.302. Asimismo, durante su implementación, especialmente en zonas urbanas, se advirtió de la omisión en la formulación de la pregunta y el marcado de la categoría "No" en el caso en el que los censistas -maestros, empleados públicos y miembros de las Fuerzas Armadas- decidían que las personas entrevistadas no poseían marcas fenotípicas correspondiente con la imágen estereotipada que esperaban encontrar de una persona indígena.

A partir de los datos de este Censo 2001, el Instituto Nacional de Estadísticas y Censos (INDEC) realizó la Encuesta Complementaria de Pueblos Indígenas dentro del período 2004-2005 (ECPI) con el objetivo de cuantificar y caracterizar a la población que a la fecha del Censo 2001 residía en hogares en base a dos criterios: el autorreconocimiento y la descendencia de un pueblo indígena en primera generación. Los criterios que guiaron el diseño de la ECPI, en términos conceptuales, fueron: mantener la inclusión de la población urbana para evitar el estereotipo que los imaginó como habitantes de un ámbito predominante (el rural), siguiendo pautas culturales tradicionales (cuyo principal exponente es el idioma); sumar otros datos, además de los ya incluidos en el año 2001, como la referencia a la ascendencia no sólo de primera generación, uso y manejo de idiomas indígenas, datos de movilidad y migración (por ejemplo, si vive o vivió en una comunidad indígena y motivo de la partida); salud y previsión social (atención de la salud, anotación en registro civil, tenencia de documento de identidad); educación; participación en organizaciones o instituciones indígenas, condiciones laborales y de seguridad social, fecundidad, entre otros (Iñigo Carrera, 2014).

Los resultados de la ECPI dieron cuenta de la significación de la presencia indígena la cual había sido históricamente negada. Esta fortaleza fue reconocida y valorada por miembros de pueblos originarios, especialmente ante el desconocimiento por parte de funcionarios estatales (Maidana, Zubrzycki \& Ottenheimer, 2014 citados en Maidana, 2019). No obstante, también se identificaron limitaciones que aluden a que la ECPI reprodujo problemas metodológicos del Censo 2001 al emplear criterios homogéneos y poco confiables como el carácter adscriptivo de pertenencia (Trinchero, 2010). Asimismo, se mantuvieron las clasificaciones de antemano, con procesos burocráticos como poseer la personería jurídica para ser reconocido como integrante de una comunidad

\footnotetext{
${ }^{10}$ Las opciones de respuesta a esta segunda parte de la pregunta se pueden ubicar en una lista de diecisiete pueblos (chané, charrúa, chorote, chulupí, comechingón, diaguita calchaquí, huarpe, kolla, mapuche, mocoví, mbya, ona, pilagá, rankulche, tapiete, toba, tupí guaraní, wichí) más otras dos categorías: "otro pueblo indígena" e "ignorado" (Trinchero, 2010; Barrientos, 2015).
} 
“indígena". También, se añade que si bien se propuso la participación de pueblos originarios en el diseño conceptual del cuestionario -mediante talleres de consulta en las distintas regiones del país- la participación no resultó completamente efectiva (Barrientos, 2015).

En esta línea, en el año 2010 se realizó el último Censo Nacional de Población, Hogares y Viviendas, en el cual además de mantenerse la pregunta por el autorreconocimiento, se consideró la cantidad de hogares y la de personas que se reconocían como descendientes de un pueblo indígena. En dicho Censo se incluyó el Cuestionario Ampliado elaborado por el INDEC. Entre los aspectos que se introdujeron para cuantificar a la población, se encuentran: fecundidad, pertenencia a pueblos originarios, población afrodescendiente, previsión social y cobertura de salud, características habitacionales del hogar, migraciones y empleo, entre otras. A su vez, estas temáticas pueden ser estimadas a niveles más agregados (Total Nacional, Provincial, etc.), ya sea directamente utilizando las técnicas usuales de estimación a partir de muestras probabilísticas, o aplicando otras herramientas, diseñadas para obtener valores a nivel de pequeños dominios (INDEC, 2015b). La incorporación de la categoría "Pertenencia a un Pueblo" fue considerado una mejora respecto del Censo de 2001, en cuanto posibilidad de contribuir a visibilizar sus colectivos de pertenencia y sus demandas (Maidana, 2019).

En suma, se puede vislumbrar dos etapas entre los primeros censos de población indígena -específicamente el CIN, el CAF y el CAP- y la inclusión de la pregunta de autopercepción en el Censo Nacional de Población 2001, la consiguiente ECPI y el Cuestionario Ampliado incluido en el Censo del año 2010. En cuanto a diferencia se encuentran que estos dos últimos relevamientos incorporaron la pregunta por la autoidentificación y se amplió a poblaciones urbanas, al buscar dejar atrás visiones estereotipadas de carácter esencialista y culturalista. En cuanto a puntos en común, podemos interpretar que muestran un legado del tipo de tratamiento estatal histórico de invisibilidad hacia la población originaria que permea en el uso de criterios homogéneos e inconsistencias al momento de realizar las preguntas; y la falta de participación de pueblos originarios en el diseño e implementación de estos instrumentos estadísticos (Trinchero, 2010).

\subsection{El tratamiento de la cuestión indígena más allá de los censos: relevamientos e informes académicos y de otras entidades no estatales.}

En las últimas cuatro décadas, en el marco de un contexto de revitalización de activismos indígenas y de reconocimiento formal-jurídico a las diversidades a nivel internacional se han incrementado las demandas de información, visibilidad, representatividad y participación, y el interés público por recabar datos desagregados de los pueblos originarios (Bengoa, 2009). No sólo los Estados siguieron las recomendaciones mencionadas de Naciones Unidas y de la Comisión Económica para América Latina y el Caribe (CEPAL), sino que también, diversos actores pertenecientes al ámbito académico y organismos no estatales elaboraron trabajos para recabar información estadística sobre los pueblos originarios. Muchas de estas producciones utilizaron las herramientas y variables estandarizadas por los dispositivos oficiales descritos anteriormente. Mientras que otras, incorporaron nuevas estrategias para construir instrumentos de recolección 
acordes a las demandas de las comunidades, e incluso contaron con participación indígena en su elaboración.

En una indagación preliminar sobre estos materiales, encontramos producciones realizadas por organismos no estatales -en su gran mayoría vinculados a instituciones religiosas internacionales- con trayectoria en el trabajo colaborativo con diversas comunidades indígenas del país. Entre ellos, Fundapaz (Fundación para el Desarrollo en Justicia y Paz), Asociana (Acompañamiento Social de la Iglesia Anglicana del Norte Argentino) y ENDEPA (Equipo Nacional de la Pastoral Aborigen).

Para ejemplificar algunas de sus producciones según dichos organismos podemos nombrar, en primer lugar, los informes sobre cantidad de población y regularización de tierras indígenas y campesinas realizados por Asociana junto con líderes indígenas nucleados en la organización interétnica Lhaka Honhat (región del Pilcomayo, provincia de Salta). Estos trabajos, realizados desde el año 2000, se desarrollaron en un escenario de demandas por el territorio y de reclamo por los desalojos ocurridos en la zona que, con posterioridad, fueron antecedentes para elaborar la Ley Nacional 26.160 (de emergencia territorial indígena) y la Ley 26.331 (Ley de Bosques). Para llevar adelante los relevamientos e identificar áreas de uso tradicional y ocupación de tierra, los representantes indígenas fueron cartógrafos y realizaron un mapeo participativo de los lotes fiscales $\mathrm{N}^{\mathrm{o}} 55$ y 14 . Se llevaron a cabo capacitaciones y talleres sobre distintos tópicos y dispositivos tecnológicos, como el uso del sistema de posicionamiento global (GPS), de georreferenciamiento, entre otras. Asimismo, para la recolección de datos se emplearon criterios que respondieron a los modos de vida y organización socioeconómica cotidiana de los propios pueblos y usos del territorio de acuerdo a pautas culturales, como lugares que ocupa cada comunidad, zonas para recolectar chaguar para artesanías o herramientas para las actividades de caza, entre otros. El resultado permitió la actualización de cifras sobre la extensión del territorio y el número de familias comuneras que ejercen la posesión comunitaria (Castelnuovo, 2019). Otra de las recopilaciones de datos e informes elaborados por esta organización tuvieron como objetivo cuantificar los desmontes y sus impactos en la población originaria en las provincias de Santiago del Estero y Salta (departamentos de Anta, San Martín y Rivadavia), especialmente ante la falta de cifras y la imposibilidad de realizar presentaciones en instancias judiciales-. Estos trabajos se realizaron de forma interinstitucional al incorporarse técnicos/as del Instituto Nacional de Tecnología Agropecuaria (INTA), que aportaron imágenes satelitales y mapeos de cultivos, logrando obtener resultados que mostraban el avance de la frontera agrícola y de empresas agroindustriales sobre territorios de pueblos originarios ocupadas por indígenas, con el correlato de aumento de la superficie desmontada y cómo afectaba a las familias de pueblos originarios que se encontraban viviendo allí (Castelnuovo, 2019).

En segundo lugar, también cabe comentar los aportes de los informes de ENDEPA ${ }^{11}$ publicados en los años 2011, 2013 y 2020, y los de la organización internacional de

\footnotetext{
${ }^{11}$ ENDEPA es un equipo eclesial católico, al servicio de los pueblos indígenas, con espíritu y búsqueda constante de una práctica ecuménica y de diálogo interreligioso. ENDEPA y cada uno de sus equipos locales, es un espacio de encuentro y diálogo de culturas, una oportunidad de ampliar la mirada, el pensamiento, los sentimientos, el espíritu y las relaciones con cada integrante y el conjunto https://www.endepa.org.ar/quienes-somos/. También Leone (2016) señala su surgimiento en la década de
} 
derechos humanos, Amnistía Internacional, de 2017. ${ }^{12}$ En ellos se sistematiza información del Instituto Nacional de Asuntos Indígenas (INAI) sobre el estado actual de la Ley 26.160, que declara la emergencia en materia de posesión y propiedad de las tierras que tradicionalmente ocupan las comunidades indígenas del país. Se presentan una serie de datos porcentuales sobre el alcance de los relevamientos técnicos-catastrales propuestos por la legislación. Su difusión ha permitido un acceso más eficiente de la información pública y sostener el reclamo de las comunidades por el incumplimiento estatal en relación a los relevamientos, objetivos propuestos y fondos económicos asignados y la falta de voluntad política para avanzar en el reconocimiento de los territorios. ${ }^{13}$ No obstante, como señala Gorosito Kramer (2008), el informe que acompañó al texto de la Ley 26.160 (2006), introduce información cuantitativa sobre los pueblos indígenas de la Argentina según diversas fuentes, organizadas por provincias y por definición étnica. Entre los registros se encuentra el Registro Nacional de Comunidades Indígenas -Re.Na.CI-, con 27 pueblos originarios distribuidos en 208 comunidades (como se recordará, estas últimas unidades de registro y reconocimiento), que aglutinan 10.307 familias y 49.924 personas. Dicha cifra no coincidía con los informes realizados por la organización católica ENDEPA, que sumó otros criterios para definir a la población como el de urbanidad (Gorosito Kramer, 2008).

ENDEPA, a través de sus Áreas de Educación y Asesoría Jurídica, ha realizado diversos informes donde sistematizó información vinculada a derechos indígenas, por ejemplo mediante la elaboración de informes alternativos o "sombra" presentados ante organismos internacionales, como así también de estudios particulares sobre una temática, difundidos para conocimiento de la sociedad en general y en busca de incidir en los responsables de gestionar las políticas públicas, como el caso de los informes "Advertencia sobre la Inejecución de las Leyes Nacionales No 26.160 y 26.554" (2011) y "Nueva advertencia sobre la inejecución de la ley 26.160 - La brecha entre las declaraciones y la realidad en materia de derechos territoriales indígenas" (2013). En el caso de la Educación Intercultural Bilingüe (EIB), donde el relevamiento de información resultó de considerar de forma participativa contando con delegados y delegadas del Equipo de Coordinación Nacional de ENDEPA todo el país; presentaciones de avances y consultas a participantes acerca de aspectos puntuales de la temática, a los efectos de obtener aportes de su experiencia y conocimiento, durante el XVII Encuentro de Educadores Indígenas (Formosa, 2018). En este espacio se contó con testimonios de líderes indígenas y agentes vinculados a la educación mediante paneles que dieron cuenta del estado de la EIB en las

1980, perteneciente a la Conferencia Episcopal Argentina, en el marco de actividades realizadas por la red de pastoral aborigen en la región chaqueña, con antecedentes en la década de 1970 como el Centro de Capacitación Zonal (CECAZO).

\footnotetext{
12 Amnistía Internacional es un movimiento mundial de activistas presentes en 162 países y territorios que se dedica a promover todos los derechos humanos consagrados en la Declaración Universal de Derechos Humanos y otras normas internacionales. Amnistía Internacional trabaja principalmente para obtener la libertad de todos los presos de conciencia; lograr que se juzgue con prontitud e imparcialidad a los presos políticos; conseguir la abolición de la pena de muerte y la erradicación de la tortura y otros tratos crueles a los presos; acabar con los homicidios políticos y las «desapariciones»; y oponerse a los abusos cometidos por los grupos de oposición. Entre sus áreas temáticas se encuentran la Protección y Promoción de los Derechos Humanos, Indígenas. Link: https://amnistia.org.ar/nosotros/; https://amnistia.org.ar/informes/?c=indigenas

13 Documentos disponibles en: https://www.endepa.org.ar/category/pubicaciones-materiales/
} 
diferentes regiones del país. Además de estos insumos se recurrió a fuentes tales como bibliografía nacional e internacional, normas jurídicas, estadísticas oficiales, documentos de organismos internacionales y de organizaciones no gubernamentales, artículos periodísticos, consultas a especialistas y a miembros de Comunidades Indígenas. Asimismo, se solicitó acceso a información pública relativa a EIB al Ministerio de Educación y Deportes de la Nación, al INAI, al Instituto Nacional contra la Discriminación, la Xenofobia y el Racismo (INADI), al Defensor del Pueblo de la Nación y a cada uno de los Ministerios de Educación o Consejo de Educación provincial y de la Ciudad Autónoma de Buenos Aires. Los ejes de las preguntas fueron sobre datos estadísticos, marco jurídico de la EIB, organismos responsables, avances, planes, programas, propuestas curriculares, materiales educativos, prácticas de enseñanza, participación indígena, formación docente inicial y continua, y carrera docente.

En tercer lugar, la Red Agroforestal Chaco Argentina (REDAF), presidida por profesionales pertenecientes a Asociana, es un espacio de articulación que reúne a personas e instituciones que trabajan en la región chaqueña y cuenta con un Observatorio de Tierras, Recursos Naturales y Medioambiente. Allí se sistematiza información que "busca dar seguimiento y visibilidad a situaciones de conflicto por la tenencia de la tierra, desmontes y deforestación, y otras problemáticas ambientales que afectan a la región chaqueña e inciden en la calidad de vida de sus habitantes, en particular comunidades campesinas e indígenas" (REDAF, página web). En uno de sus informes del año 2011 sobre tenencia de la tierra en la región de Chaco se relevaron 248 conflictos lo que se tradujeron en 2.791.302 hectáreas. En el 94\% de los casos los afectados carecían de título de propiedad. ${ }^{14}$ Este tipo de producciones que sistematizan información recolectada en los territorios son fundamentales para conocer y hacer visibles los problemas y conflictos existentes, su evolución y consecuencias, como también, informar y poner a disposición a actores interesados para realizar propuestas e incidir en decisiones políticas o para que puedan utilizarlos en la defensa de sus derechos.

En cuarto lugar, respecto a relevamientos elaborados por organismos internacionales, se encuentran otros informes ofrecidos por Amnistía Internacional. Uno de ellos trata sobre la vulneración de derechos humanos del pueblo wichí y qom en la provincia de Formosa durante la pandemia generada por el virus SARS-CoV-2. El trabajo utiliza información censal (Censo 2010) y la proporcionada por otras organizaciones (como APCD, EDIPA, Parroquia María de la Merced, Fundación Manos de Hermanos y Centro Barrial Enrique Angelelli). También, combina los datos cuantitativos con otros testimonios obtenidos de conversaciones con las propias personas afectadas, entrevistas telefónicas con distintos actores intervinientes en los casos relevados (abogados/as representantes), solicitudes de acceso a la información pública y el relevamiento de noticias, imágenes y videos difundidos públicamente. ${ }^{15}$

En esta línea, en quinto lugar, ubicamos los producidos por el Relator de Pueblos Indígenas de la ONU. ${ }^{16}$ Por caso, el informe presentado al relator James Anaya (2011) y

\footnotetext{
14 Conflictos sobre tenencia de tierra y ambientales en la Región Chaco Argentina, $3^{\circ}$ Informe. Datos relevados hasta agosto del 2011.

${ }^{15}$ Link: https://amnistia.org.ar/wp-content/uploads/delightful-downloads/2021/10/Covid-19-y-DerechosHumanos.-La-situaci\%C3\%B3n-de-la-provincia-de-Formosa-Argentina-1-3.pdf

${ }^{16}$ Link: https://www.ohchr.org/sp/issues/ipeoples/srindigenouspeoples/pages/sripeoplesindex.aspx
} 
al Comité de Derechos Económicos, Sociales y Culturales (2011). El mismo fue elaborado por distintas agrupaciones, donde se señalan las falencias en la información brindada por el Estado argentino que imposibilitan contar con un diagnóstico preciso sobre los niveles concretos de cumplimiento de las obligaciones que emanan del Pacto Internacional de Derechos Económicos, Sociales y Culturales ${ }^{17}$. Las fuentes consultadas son diversas e incluyen a las estatales, intergubernamentales y no gubernamentales, las audiencias celebradas ante la Comisión Interamericana de Derechos Humanos (CIDH) y las alertas enviadas por los medios y comunicadores. Entre los resultados presenta el relevamiento del estado de incumplimiento de derechos indígenas como ocurre con la inejecución del relevamiento jurídico catastral incluido en la Ley 26.160 y de los conflictos territoriales con cifras de territorios afectados y comunidades involucradas.

En continuidad con este corpus de trabajos realizados por organizaciones no estatales, identificamos una serie de producciones llevadas a cabo en el ámbito académico, sobre todo vinculadas a Universidades públicas u organismos estatales de Ciencia y Técnica como el Consejo Nacional de Investigaciones Científicas y Técnicas (CONICET). En ellas encontramos determinadas producciones que brindaron aportes innovadores para cuantificar datos en clave indígena o, al menos, profundizar en otros aspectos a los ya mencionados indicadores oficiales. Por ejemplo, en el año 2017 se generó un Convenio de Cooperación Técnica y Asistencia Recíproca entre el Defensor del Pueblo de la Provincia de Buenos Aires y la Universidad Nacional de La Plata (UNLP)-Facultad de Ciencias Naturales y Museo (FCNyM). El objetivo fue confeccionar un "Protocolo de actuación para organismos gubernamentales de la provincia de Buenos Aires" (Maidana, 2019: 250). Para realizar dicho trabajo, se recuperaron cifras censales, una síntesis del marco jurídico referido a pueblos indígenas y una serie de recomendaciones que fueron resultado de una construcción colectiva, de una producción de conocimiento conjunto (Tamagno et al., 2005 citada en Maidana, 2019). Esta información y lineamientos generales atendieron a las demandas de personas, comunidades y pueblos indígenas por la efectivización de sus derechos e implicaron la colaboración con instituciones académicas sobre temas de derechos humanos.

También, nos parece oportuno señalar la Encuesta Nacional sobre la Estructura Social (ENES) realizada por el Programa de Investigación sobre la Sociedad Argentina Contemporánea (PISAC). El objetivo del relevamiento fue conocer estructuralmente la heterogeneidad de la sociedad argentina contemporánea en sus múltiples manifestaciones: sociales, culturales, políticas y económicas. De manera que en la

\footnotetext{
${ }^{17}$ Las agrupaciones participantes fueron: Centro de Estudios Legales y Sociales (CELS), Observatorio de Derechos Humanos de los Pueblos Indígenas (ODHPI), Servicio de Paz y Justicia (SERPAJ), Centro de Políticas Públicas para el Socialismo (CEPPAS), Grupo de Apoyo Jurídico para el Acceso a la Tierra (GAJAT), Abogados y Abogadas del Noroeste Argentino en Derechos Humanos y Estudios Sociales (ANDHES), Equipo Patagónico de Abogados y Abogadas en Derechos Humanos y Estudios Sociales (EPHADES), Secretaría con relación de Pueblos Originarios de la CTA, Equipo Nacional de Pastoral Aborigen (ENDEPA), Movimiento de Profesionales para los Pueblos (MPP), Organización de Comunidades de Pueblos Originarios (ORCOPO), Comisión de Juristas Indígenas en la Rep. Argentina (CJIRA), Comisión Provincial por la Memoria Fundación para el Desarrollo en Justicia y Paz (FUNDAPAZ), Defensoría General de la Nación, CÁTEDRA LIBRE DE PUEBLOS ORIGINARIOSUNPSJB Comisión de Pueblos Originario e Inmigraciones de la Secretaría de Extensión de la Facultad de Trabajo Social de la UNLP, Comisión de Derechos de los Pueblos Originarios y neoconstitucionalismo de la UBA, Asociación de Abogados de Derechos Indígena (AADI).
} 
encuesta se incorporaron, a la ya clásica pregunta de autopercepción indígena, otras referidas al idioma y el origen geográfico de cada entrevistado. Uno de los mayores beneficios de este trabajo es la disponibilidad pública de las fuentes primarias, ya que se permite acceder a la matriz de datos y cruzar los indicadores indígenas con un conjunto de variables "novedosas" en los estudios sociales, como la autopercepción de clase ${ }^{18}$.

Finalmente, nos interesa señalar dos experiencias realizadas por las autoras de este artículo. Por un lado, en el marco de la producción de una tesis doctoral, un trabajo de elaboración y coordinación de un relevamiento de las condiciones socioeconómicas de las familias de campesinos qom pertenecientes a la Federación Nacional Campesina en Pampa del Indio, en la provincia de Chaco (Colla, 2015). El objetivo consistió en producir datos actualizados sobre la población indígena que vivía en zonas rurales y de manera dispersa a los fines de pensar, formular y coordinar acciones políticas y/o legales que contribuyan a reactivar la producción de las unidades campesinas y mejorar sus condiciones de vida. El relevamiento socio productivo se realizó a 250 familias y tuvo carácter muestral a partir de la pertenencia de las familias censadas por los integrantes de dicha Federación. Lo novedoso del relevamiento consistió en pensar la unidad de análisis desde los núcleos y vínculos familiares, y no meramente como unidades socioeconómicas. El trabajo de campo consistió en la elaboración de un cuestionario breve, traducido al idioma Qom La'aqtac y difundido entre los delegados indígenas de la organización, quienes llevaron a cabo la recolección de datos casa por casa. Luego, se procedió a la carga de las planillas en formato Excel (a cargo de jóvenes indígenas), que más tarde fueron procesadas con el programa de análisis estadístico SPSS. El informe técnico final se puso a disposición de la organización y se convirtió en una herramienta para mantener en vigencia la acción de amparo del Defensor del Pueblo de la Nación promulgada en 2007, que instaba al gobierno de la provincia de Chaco a adoptar medidas de asistencia humanitaria y social para la población indígena que se encontraba, según dicha resolución, en "situación de exterminio silencioso, progresivo, sistemático e inexorable" (D. 587. XLIII).

Por otro lado, un trabajo, donde participan las autoras, de diagnóstico sobre la situación actual de los diversos pueblos originarios en nuestro país. Dentro de un equipo interdisciplinario e interinstitucional se analizan los resultados estadísticos del Cuestionario Ampliado del Censo Nacional de Población 2010 con otros datos ofrecidos por el "Informe ampliado: efectos socioeconómicos y culturales de la pandemia COVID19 y del aislamiento social, preventivo y obligatorio en los Pueblos Indígenas en Argentina -Segunda etapa, junio 2020-" (Abeledo, 2020) y los construidos a partir de trayectorias propias de investigación de largo aliento. Resulta necesario aclarar que en el caso de este informe, la metodología utilizada para la construcción de datos se basó en entrevistas telefónicas, videollamadas y encuestas -dada la situación de restricción de circulación por la pandemia-, que fueron analizadas junto a datos secundarios provenientes de trabajos académicos y estadísticos, información de organismos públicos, notas periodísticas, entre otros. ${ }^{19}$ Asimismo, dicho informe fue realizado entre diversos

\footnotetext{
${ }^{18}$ Base de datos disponible en: https://datos.gob.ar/dataset/mincyt-pisac---programa-investigacion-sobresociedad-argentina-contemporanea/archivo/mincyt_2141ff0e-9840-4da0-827e-f460d4f52f82

${ }^{19}$ Conformado por profesionales de distintas disciplinas -Antropología, Sociología, Ciencia Política, Historia, entre otras- e instituciones junto con referentes indígenas a lo largo de todo el país. El objetivo fue realizar un diagnóstico del impacto económico, social y cultural que la pandemia y las medidas establecidas
} 
equipos, instituciones universitarias y los pueblos, y sus comunidades indígenas a través de sus referentes y organizaciones representativas. Considerando estos antecedentes y la combinación de múltiples fuentes, la mirada de esta iniciativa parte de triangulaciones entre las cifras oficiales, los propios datos obtenidos de las investigaciones realizadas, los datos generados desde los propios pueblos originarios y de otras organizaciones no estatales, asociaciones y fundaciones vinculadas. De esta forma se realizan lecturas y análisis cruzados entre las diversas variables -adscriptivas, socioeconómicas, demográficas y territoriales.

Hasta aquí podemos señalar que todas estas producciones poseen ventajas y limitaciones respecto a la información que proporcionan. En cuanto a los alcances, se encuentran la inclusión de nuevas categorías al momento de relevar la situación de los pueblos originarios y su cuantificación, las cuales no sólo toman el carácter adscriptivo, sino también las territoriales -estado de relevamientos de los territorios, sus usos, desmontes, entre otros-. Este punto de partida, con nuevas consideraciones y diversas fuentes que incluyen a las oficiales, permite ampliar el abordaje y, por lo tanto, obtener cifras e información más exhaustiva y contextualizada por los casos trabajados.

Respecto de sus limitaciones podemos decir que en los relevamientos organizados por movimientos sociales, fundaciones, asociaciones y la academia también subyacen formas de definir a los pueblos originarios, que inciden en la producción de información. Para el ejemplo citado de Asociana la academia tuvo un lugar central en las representaciones que se fueron consolidando sobre los pueblos indígenas del Gran Chaco. El rótulo que recibió el pueblo wichí partía de caracterizarlo como "cazador-recolector" a partir de ciertos atributos que parecerían serles inmanentes, tales como el de una "conciencia ecológica" que los mantiene alejados de ciertas prácticas económicas (como la tala de madera) que son percibidas como contrarias a su idiosincrasia y su forma de relacionarse con la naturaleza. En el caso de Fundapaz, varios de sus integrantes cuestionan la vigencia del modelo cazador-recolector indígena, debido a que encuentran una asociación a una cierta visión antropológica, indigenista y esencialista alejada de la realidad y el presente (Castelnuovo, 2019). Otro ejemplo de esencialismo es, como señala Laura Zapata (2014), con casos como ENDEPA, donde en tanto actores de apoyo a las demandas territoriales de los pueblos originarios, introdujeron el concepto de pueblo indígena en los lenguajes políticos y jurídicos de Argentina en las últimas décadas, asociando el concepto de indianidad con ruralidad. En síntesis, creemos que estos materiales, muchos de ellos elaborados en conjunto con pueblos indígenas y sus comunidades permiten delinear otras opciones viables para cuantificar y producir datos sobre los pueblos indígenas, incluso en clave intercultural, lo que aporta una perspectiva que enriquece el trabajo, y que podría considerarse como horizonte metodológico para el futuro.

\section{Métodos cuantitativos. Alcances y debates en torno a la formulación de las variables de análisis en la producción de estadísticas.}

en nuestro país tuvieron sobre los pueblos indígenas en las distintas regiones: Cuyo, Metropolitana, Noreste, Noroeste, Pampeana y Patagónica. Además, se buscó generar insumos para la toma de decisiones o la elaboración e implementación de políticas públicas (Aljnati, et al., 2021). 
Partimos del supuesto de que los métodos cuantitativos y cualitativos, o su triangulación, son apropiados para alcanzar distintos objetivos cognitivos y tratar problemas de índole diferente. En este sentido, la tarea del investigador no es aferrarse acríticamente a un modelo, sino tomar las decisiones técnicas pertinentes en función del problema de investigación que enfrenta (Marradi, 1994).

Las potencialidades o ventajas que encontramos en el uso de técnicas de cuantificación en poblaciones indígenas refieren a las posibilidades de comprender y visibilizar la construcción de la etnicidad -en sus dos frentes- en la dinámica de los fenómenos sociales. En otras palabras, permite establecer relaciones entre propiedades, fundándolas en algo más que impresiones y cuantificando la fuerza de estas relaciones en asociaciones -más no en causalidades- (Marradi, Archenti y Piovani, 2010).

En esta línea, tanto las herramientas censales y, con ellas, la posibilidad de realizar asociaciones entre el auto reconocimiento, la pertenencia a un pueblo indígena y otras variables socioeconómicas -como los disponibles en el censo de $2010-{ }^{20}$. O también, otros relevamientos o encuestas elaboradas para distintos informes sobre temáticas específicas, han permitido visibilizar la presencia de colectivos indígenas con identidades históricamente negadas y describir fenómenos sociales a gran escala, vinculados a la apropiación de tierras, estado de cuestión de legislaciones específicas - como los informes sobre ley $26.160-$, entre otros.

Esto se ha traducido en valoraciones positivas por parte de referentes y funcionarios indígenas para visibilizar la presencia territorial y las demandas de las poblaciones en base a sus condiciones socioeconómicas. Asimismo, los datos potenciaron la elaboración de políticas públicas específicas que permitieron mejorar la implementación de derechos. También, habilitaron la elaboración de recursos judiciales de amparo, como el esgrimido por el Defensor del Pueblo de la Nación en el año 2007 que condenó al Estado nacional y a la provincia del Chaco a adoptar las medidas necesarias para modificar la condición de vida de los habitantes del pueblo qom de las regiones sudeste de esa provincia, en virtud de la situación de emergencia extrema y de necesidades básicas y elementales insatisfechas. Dicha demanda fue realizada en base a información estadística proporcionada por ONG's (CSJ 587/2007 (43-D)/CS1). ${ }^{21}$

Junto con esto, la Organización de las Naciones Unidas (ONU) (2014) señaló que las estadísticas oficiales constituyen un elemento indispensable en el sistema de información de una sociedad democrática y proporcionan al gobierno, a la economía y al público datos acerca de la situación económica, demográfica, social y ambiental. Entre los principios para su uso se encuentran: relevancia, imparcialidad y acceso equitativo; patrones profesionales, principios científicos y ética que permitan la confianza sobre los métodos y procedimientos para la construcción, el procesamiento, el almacenamiento y la presentación de los datos estadísticos; responsabilidad y transparencia con el fin de facilitar una interpretación correcta de los datos; prevención del mal uso u observaciones

20

https://redatam.indec.gob.ar/argbin/RpWebEngine.exe/PortalAction?\&MODE=MAIN\&BASE=CPV2010 A\&MAIN=WebServerMain.inl

${ }^{21}$ Link:

https://sjconsulta.csjn.gov.ar/sjconsulta/documentos/verDocumentoById.html?idDocumento=7651841 
sobre interpretaciones erróneas y la utilización indebida de las estadísticas; fuentes de estadísticas oficiales de calidad, la oportunidad, el costo y la carga que impondrá a los encuestados; confidencialidad de aquellos datos de personas naturales o jurídicas, entre otros.

En efecto, es posible afirmar que la disponibilidad y difusión de datos relativos a esos pueblos puede: "a) contribuir a investigaciones sobre la situación socioeconómica de las poblaciones indígenas, tendencias, causas de desigualdad y eficacia de las políticas y programas vigentes; b) ayudar a las comunidades indígenas a evaluar sus condiciones de vida y ofrecerles información que necesitan para participar en la elaboración y promoción de programas y políticas que afectan a sus comunidades (en materia de salud, producción económica, ordenación ambiental y organización social). Y, finalmente, la elaboración de indicadores relacionados con la población indígena y su medición en el proceso de recopilación de datos puede utilizarse para supervisar el desarrollo humano de las poblaciones indígenas" (Iñigo Carrera, 2014:11).

No obstante, cabe mencionar que en la práctica concreta de las distintas agencias, funcionarios estatales y movimientos indígenas, el acceso a las fuentes de información estadística suele ser dificultoso. Esto puede deberse a la falta de difusión de los resultados de los relevamientos censales (en el caso argentino, a cargo del Instituto Nacional de Estadísticas y Censos) o la presentación de los datos con idioma técnico o recursos linguísticos que imposibilitan la recepción y apropiación por parte de los funcionarios públicos, personas o comunidades indígenas. A esto se suma que existe cierta desconfianza metodológica en la comunidad académica sobre las fuentes primarias o se cuestiona sobre los alcances y pertinencia de los dispositivos para cuantificar la diversidad de identidades y condiciones de vida de las poblaciones indígenas. Al respecto es necesario tener en cuenta algunas consideraciones metodológicas que interpretamos como limitaciones para la elaboración de datos estadísticos sobre las realidades de los pueblos indígenas.

En Ciencias Sociales ha sido un tema recurrente el debate teórico, metodológico y epistemológico sobre la posibilidad de cuantificar -bajo variables relativamente cerradasaspectos subjetivos de la realidad, en especial de la identidad y la autopercepción de clase social. En relación a los pueblos indígenas este debate trasciende también al ámbito político, puesto que la visibilización supone diversos diagnósticos sobre los estereotipos construidos en torno a la sociedad argentina. En la literatura especializada fue planteado el desafío que representaba abordar las identidades indígenas atendiendo a los contextos de modernidad y globalización, bajo una noción dinámica, relacional y flexible de los procesos sociales (Vázquez, 2000; Valdivia Vargas, 2011; Barrientos, 2015). Como se mencionó previamente, si bien en Argentina existe cierto consenso en la utilización de la autoadscripción para aludir a la pertenencia a un pueblo originario, continúa siendo una dimensión subestimada dentro del operativo censal (en términos de espacio en la planilla e instrucción técnica de los censistas para formular la pregunta que construye dicha variable). Las preguntas diseñadas para la autoidentificación étnica presentan un problema de comprensión. Presumiblemente, el no captar el sentido de la pregunta se deriva del hecho de no comprender el significado de la interrogante ni de las opciones de respuesta presentadas (Valdivia Vargas, 2011; Barrientos 2015). 
Respecto del método cuantitativo de asociación, existe cierta desconfianza en la comunidad científica por su carácter homogeneizador y estandarizado. Esto va en línea con los criterios de generalidad, objetividad y externalidad, propios del método cuantitativo. Al respecto, Marradi, Archenti y Piovani (2010) señalan tres prácticas inadecuadas difundidas en el método de asociación utilizado como enfoque estándar en ciencias sociales, es decir, en la herramienta de la matriz de datos donde se disponen vectores horizontales que responden a objetos (individuos, familias, grupos, instituciones, etc.) y vectores verticales que responden a sus propiedades. El tipo de objeto sobre el que se busca información, en el caso del Censo, por ejemplo, hogares donde un miembro se autopercibe como perteneciente a algún pueblo indígena, se llama unidad de análisis. Ella es, a su vez, la expresión en abstracto de una investigación social que integra, a su vez, un espacio-temporal en donde se encuentra un conjunto de ejemplares de esa unidad: la población. La "muestra" es cualquier subconjunto, amplísimo o limitadísimo, de miembros de una población que se investiga con el fin de extender a toda la población las conclusiones resultantes del análisis de las informaciones relativas al subconjunto. Esta extrapolación (de los resultados al análisis) de la muestra a la población entera es llamada inferencia estadística.

Al respecto, los autores antes mencionados señalan tres prácticas inadecuadas muy difundidas en las ciencias sociales que, en el caso aquí analizado, generan acepciones en la elaboración de resultados estadísticos relativos a las realidades de los pueblos indígenas.La primera es una costumbre terminológica y consiste en hablar de inferencia de la muestra al universo. Este uso es impropio, puesto que el universo es finito mientras que la población no lo es. En otras palabras, no es posible extender los resultados de una encuesta (pensemos en la ECPI realizada en el año 2004) a conjuntos infinitos, es decir, universos. La segunda consiste en el hábito de extender la inferencia más allá de la población de la cual se extrajo la muestra.

La tercera acepción inadecuada es la declaración de muestras aleatorias y representativas. Es decir, una muestra aleatoria es cuando todos los miembros de la población de la que se extrae la muestra tienen la misma probabilidad de ser extraídos y entrar en la muestra (esto sucede generalmente con una entrevista realizada en la calle). Para construir una muestra aleatoria de una población se debe elaborar un listado completo de sus miembros y extraer algunos de ellos con una tabla de números aleatorios o algún procedimiento que garantice efectivamente la misma. En sintonía, Rosana Guber $(2005,2011)$ señala que la muestra probabilística permite informar sobre distribuciones de frecuencia con respecto a datos cuantificables al considerar a los informantes como unidades discretas. Sin embargo, resulta fundamental recordar que es el/la investigadora quien establece los criterios de clasificación para definirla en base a los objetivos de la investigación, y que dicha muestra puede resultar insuficiente si lo que se busca es comprender la dinámica social, modos organizativos, sentidos por los que se orientan sus miembros, especialmente los inesperados o desconocidos por el investigador.

En suma, encontramos que el uso de herramientas estadísticas resulta beneficioso para analizar la adscripción de la población a pueblos originarios y poder cruzar estos datos con indicadores estructurales como el NBI, ocupación y condiciones habitacionales. Esta técnica, entonces genera la posibilidad de construir datos estadísticos que nos permitan acercarnos a la manera en que viven las comunidades, a su situación socioeconómica, así 
como también dar cuenta del impacto y de la eficacia de las políticas y programas vigentes (Iñigo Carrera, 2014)

En función de lo anterior, si entendemos que la información estadística es producto de la construcción de datos y, por ende, de actos clasificatorios -desde el diseño, asignación de valor, descripción o síntesis de la información obtenida-, se encuentran distintas limitaciones referidas a los alcances y pertinencia de los dispositivos para cuantificar la diversidad de identidades y condiciones de vida de las poblaciones indígenas. Específicamente, la reproducción por sesgos extractivistas, culturalistas, esencialistas y eurocentristas que definen a priori a los pueblos originarios como sujetos homogéneos. Este abordaje impide reconocer su dimensión histórica y trayectorias de los pueblos indígenas y su situación actual; además de generar subregistros e inconsistencias. Por último, entendemos que si se diera una discusión más amplia de los resultados, sumado a una presentación de los mismos en un lenguaje accesible para audiencias que incluyeran a la población en general (y en especial a las personas y comunidades indígenas), así como a funcionarios públicos y técnicos, los mismos podrían ser mejor aprovechados. Del mismo modo, entendemos que si se construyera la información estadística a partir de técnicas cuantitativas y se sumará a este proceso distintas voces y perspectivas de los pueblos originarios en clave intercultural, el trabajo se vería enriquecido.

\section{Interdisciplinaridad, abordajes teórico/práctico y alteridades}

En función del recorrido realizado sobre los usos de relevamientos estadísticos oficiales e impulsados por actores no estatales, y al identificar tanto las ventajas que ofrecen como sus sesgos, nos resulta importante desarrollar el abordaje interdisciplinario que tiene lugar en estas páginas en pos de comprender la realidad compleja de las poblaciones indígenas en Argentina, así como la problematización y definición el concepto de etnicidad. Cabe comentar que, si bien las trayectorias formativas de quienes escribimos este artículo son diversas, el análisis sobre los aportes de un trabajo interdisciplinario lo centraremos en los casos de construcción de datos estadísticos que presentamos en los apartados anteriores.

Este artículo surgió de nuestras experiencias de trabajo, y es a partir de ellas que nos proponemos los siguientes interrogantes: ¿cómo pensar y construir la variable indígena en los instrumentos estadísticos de forma no dicotómica, esencializada y/o objetivada?, ¿cómo evitar reproducir históricas representaciones y tratamientos estigmatizantes hacia los pueblos originarios? Especialmente cuando, como hemos mostrado, la academia ha tenido una activa participación e influencia en el diseño -modos de categorizar- e implementación de los relevamientos estadísticos, con impacto en la legitimación de la presencia y demandas de pueblos originarios en nuestro país (Maidana, 2019). Asimismo, si consideramos que toda producción de conocimiento, especialmente en torno a las diversidades y etnicidades, se enmarca en un entramado de relaciones de poder, que puede adquirir un sentido negativo-clausurante o positivo-potenciador. En el primer caso opera reproduciendo desigualdades y estructuras de poder de dominación coloniales; en el segundo caso, persigue cuestionarlas, exhibirlas y modificarlas (Carrasco, Sánchez y Tamagno, 2012; Katzer, 2019). Identificamos, a continuación, tres consideraciones que invitan a repensar tanto dichas formas de producción de conocimiento, para el caso que 
nos aboca, como el uso de los instrumentos cualitativos, y la elaboración de múltiples criterios y categorías.

Un primer aspecto central consiste en entender a la interdisciplinariedad y, a la vez, al trabajo intersectorial e interinstitucional como formas de organización y amplitud donde diferentes especialistas y disciplinas debaten aspectos de una misma problemática, buscan interconexiones, influencias mutuas y retroalimentaciones para que cada especialista aproveche no sólo los conocimientos, sino la manera de pensar y encarar los problemas habituales de los demás enfoques disciplinares. En este sentido, se diferencia de posturas monodisciplinares -un equipo dirigido por una disciplina donde el resto cumplen el rol de colaboradores, y de aquellas multidisciplinarias, cuando una misma problemática es trabajada desde diferentes ángulos y especialistas, pero sin una articulación conjunta (Elichiry, 2009; Trinchero y Petz, 2014). El punto de partida debe ser integral si retomamos que las herramientas cuantitativas para producir datos estadísticos construyen datos donde el/la investigador/a, asesor/a es quien establece los criterios para definirlas y que, por lo tanto, la definición de la población indígena puede realizarse de muchas maneras, por ejemplo, mediante una pregunta sobre el origen étnico (es decir, los antepasados) y/o la identidad autopercibida como indígena.

En el diseño y revisión de las definiciones y categorías de la variable indígena, se requiere un trabajo interdisciplinario que permita comprender la dinámica social, modos organizativos, sentidos por los que se orientan sus miembros. De esta manera, los aportes de los distintos campos de conocimiento contribuyen a construir una imagen más general y acabada de la realidad que se busca conocer.

Un segundo aspecto, en consecuencia, es que el trabajo interdisciplinario se encuentra en estrecha relación con una dialéctica subjetividad/objetividad, pensada nuevamente no de forma dicotómica, sino al resaltar que la producción debe considerar niveles micro -datos de la organización comunitaria, modos de vida, entre otros- y macro -datos generales sobre condiciones de salud, trabajo, movilidad, entre otros-. Estos interjuegos permiten reconocer también la diversidad de esta subpoblación (Iñigo Carrera, 2014).

Un tercer aspecto central consiste en que el enfoque que sostenemos de trabajo interdisciplinario parte de una mirada no tradicional o hegemónica institucionalizada donde el conocimiento se encuentra planteado unidireccionalmente. Por lo tanto, el saber se vincula con las lógicas de producción relacional y de circularidad dialéctica del conocimiento o un enfoque interepistémico (Maidana, 2019). En otros términos, nos referimos a perspectivas que promueven una construcción colectiva y participativa del conocimiento donde los distintos actores que participan -académicos y no académicos- se encuentran en posiciones de decisión similares, o al menos, no jerárquicas y asimétricas (Trinchero y Petz, 2014; Naidorf y Perrota, 2015; Manzano, 2019). Dichas modalidades parten de la premisa de que no hay saber universal elaborado desde la academia, sino que existen múltiples voces, cosmogonías, configuraciones, articulaciones disciplinares, intersectoriales y comunitarias del conocimiento vinculadas a diversas condiciones de producción y, por lo tanto, que el intercambio y la colaboración entre ellas son imprescindibles (Petz, 2008; Maidana, 2019). Este punto es central, si consideramos que una de las críticas de los censos oficiales es el eurocentrismo y la falta de participación de pueblos originarios y sus organizaciones en su diseño e implementación. En 
contraposición, proponemos que su efectiva participación reducirá la reproducción de estereotipos, homogeneizaciones e inconsistencias producto de la herencia histórica de invisibilidad hacia los pueblos originarios como desconocimientos por parte de quienes investigamos. Asimismo, entendemos necesario cuestionar el tratamiento paternalista que conciben a los pueblos originarios como sujetos pasivos, sino como productores de conocimiento (Trinchero y Petz, 2014).

Por último, sería interesante pensar, como horizonte a futuro, en una propuesta censal en clave intercultural además de interdisciplinaria, apuntando a un movimiento epistemológico que considere la participación de los pueblos indígenas, en pos de enriquecer la construcción de información estadística. Esta propuesta posibilitaría compartir, intercambiar y poner en tensión estos variados saberes y conocimientos que, desde esta mirada, son comprendidos y valorados en su complementariedad (Maidana, 2019). Para lograrlo, entendemos que es fundamental transformar la manera de hacer investigación, y un punto de partida podría ser el de alejarnos del trabajo "sobre" determinada población o grupo, para hacerlo "con" ellos en forma articulada y mancomunada (Mato, 2014).

\section{Reflexiones finales}

En este trabajo indagamos en los alcances del método cuantitativo en pos de conocer la presencia de los pueblos indígenas en Argentina. Para ello, nos fue necesario partir de dos consideraciones. Por un lado, comprender el uso de los instrumentos metodológicos que permiten construir resultados estadísticos desde el concepto de etnicidad, en tanto, permite un análisis dinámico y no dicotómico que contempla tanto construcción políticoideológica realizada por el Estado como la identidad política indígena que se manifiesta en las distintas estrategias de resistencia y cuestionamiento a las lógicas clasificatorias impulsadas por los pueblos originarios y sus organizaciones. Por el otro, entendemos que al momento de definir dicho instrumento, la elaboración de las variables y sus categorías son una construcción elaborada por investigadores y/o técnicos, es decir que no están dadas a priori o de forma "natural".

De esta manera, describimos -sin agotar la totalidad de casos y experiencias- diferentes relevamientos y sus productos estadísticos. En primer lugar, identificamos los usos estadísticos en distintos momentos históricos mediante los censos nacionales destinados específicamente a relevar y cuantificar a los pueblos originarios. Dimos cuenta que la construcción de la variable indígena no puede ser desvinculada de la relación entre el Estado, actores no estatales y los pueblos originarios debido a que las estadísticas oficiales son dispositivos que permiten, como mencionamos, construir datos numéricos de dicha población, así como también recrear y sostener ciertos imaginarios nacionales, cartografiar a la población, sus relaciones de poder e intervenir en ellas. El CIN, el CAF y el CAP plasmaron los históricos procesos de invisibilidad y asimilacionismo hacia la población indígena. Luego, la inclusión de la pregunta de autopercepción en el Censo Nacional de Población 2001, la consiguiente ECPI y el Cuestionario Ampliado en el Censo del año 2010, enmarcados en un contexto de reemergencia étnica, activismos políticos y cambios de derecho -reconocimiento formal a la diversidad étnico-cultural-, incorporaron la pregunta por la autoidentificación y se ampliaron los criterios de medición para dejar atrás visiones estereotipadas de carácter esencialista y culturalista. 
En segundo lugar, y ante las limitaciones de la cuantificación oficial -legado de definiciones y clasificaciones de la población sesgada y la falta de participación de pueblos originarios en el diseño y elaboración de estas herramientas- incorporamos otros relevamientos generadas por instituciones académicas, ONG's o por los propios pueblos indígenas. Éstos reflejan la diversidad de producciones realizadas y el uso generalizado de las estadísticas complementados con otros métodos cualitativos. No exentos de tensiones y contradicciones, destacamos trabajos en clave intercultural, y la visibilidad y producción de cifras vinculadas a distintas problemáticas territoriales que aquejan históricamente a los pueblos originarios.

La recuperación por estos ejemplos de relevamientos oficiales y de aquéllos generados por otros actores no estatales nos permitió vislumbrar y profundizar en las ventajas y desventajas que encontramos en el uso del método cuantitativo para elaborar resultados estadísticos. En cuanto a las primeras reconocemos la posibilidad de: a) contribuir a visibilizar la presencia indígena en nuestro país que históricamente ha sido negada; b) vincular distintos datos -demográficos, socioeconómicos, habitacionales, de ocupación, educativos, sanitarios, entre otros-, lo cual brinda un diagnóstico acerca de la situación socioeconómica actual de los pueblos; c) realizar análisis de evaluación de los resultados e impactos de las políticas públicas, sus grados de cumplimientos e incumplimientos; d) ofrecer información necesaria para participar en la elaboración y promoción de programas y políticas que afectan a sus comunidades (en materia de salud, producción económica, ordenación ambiental y organización social); y e) finalmente, la elaboración de indicadores relacionados con la población indígena y su medición en el proceso de recopilación de datos puede utilizarse para supervisar el desarrollo humano de las poblaciones indígenas.

Por su parte encontramos limitaciones en el uso del método aquí comentado cuando éste es pensado de forma aislada, objetivante y "neutral", es decir, como producto de recolección de datos que están per se en la realidad, y no como una construcción de esos datos y de selección de muestras representativas donde intervienen criterios y lógicas de quienes definen y diseñan la variable indígena. Entre ellas se encuentran la reproducción de miradas culturalistas, esencialistas y eurocéntricas que definen a priori a los pueblos originarios como sujetos homogéneos. Los riesgos de este abordaje son la falta de reconocimiento de la dimensión histórica y trayectorias de los pueblos indígenas y su situación actual; además de generar subregistros e inconsistencias. Otras limitaciones está en el hábito de extender la inferencia más allá de la población de la cual se extrajo la muestra. Se encuentran también la falta de difusión de los resultados, su presentación en lenguajes técnico, o la no traducción a idiomas de los pueblos originarios que imposibilitan la recepción y apropiación por parte de los funcionarios públicos, personas o comunidades indígenas; y la falta de participación de pueblos originarios en el proceso de diseño e implementación de estos instrumentos.

Además, como propuesta y horizonte de cara al futuro, indicamos el trabajo interdisciplinario, interinstitucional, e intercultural, junto con la necesidad de retomar la denominada triangulación de métodos cualitativos y cuantitativos para alcanzar distintos objetivos cognitivos y tratar problemáticas de índole diferente, especialmente con pueblos originarios y su histórica relación de subalternización, subordinación y explotación. La valoración y propuesta a seguir de enfoque refleja la forma de trabajo de las autoras, 
quienes proceden de trayectorias formativas y equipos de trabajo diversos. También, la necesidad de encontrar otros abordajes y modalidades de investigación para algunos de los interrogantes que emergen del recorrido analítico realizado en este artículo desde una mirada dinámica de la etnicidad: ¿cómo pensar y construir la variable indígena en los instrumentos estadísticos de forma no dicotómica, esencializada y/u objetivada?, ¿cómo evitar reproducir históricas representaciones y tratamientos estigmatizantes hacia los pueblos originarios?, ¿qué rol asumen los mismos pueblos originarios y sus organizaciones en la producción de estos relevamientos?

En suma, concluimos que una propuesta de uso de estadísticas censales en clave interdisciplinaria permitirá recuperar los beneficios que ofrecen las estadísticas, atender a sus dificultades y, a partir de este reconocimiento, ponderar la complementariedad con otros métodos cualitativos. Además, y no menos importante, avanzar hacia formas de producción de conocimiento y de datos que sean contextualizados y que permita exhibir, cuestionar y modificar los sesgos presentados que afectan a la visibilidad de los pueblos originarios y sus demandas.

\section{Referencias bibliográficas}

Aljanati, L.; Barbosa Becerra, J.; Bompadre, J. M.; Brown, A.; Castelnuovo Biraben, N.; Cherñavsky, S.C.; Colla, J.; Engelman, J.; Golé, C.; Gerrard, A.C.; Herrera, V.; Maidana, C.; Morey, E.; Quispe, L.; Radovich, J.C.; Reinoso, Paula; Schmidt, M.; Tamagno, L. Tolosa, S.; Valverde, S.; Varisco, S.. (2020). "Pueblos Indígenas Y Covid-19 En Argentina. Principales Lineamientos De Un Informe Colaborativo". Colección Puentes, Editorial De La Facultad De Filosofía y Letras, UBA.

Balazote, A. A. (2015). "Pueblos Originarios: disputas en el campo discursivo"-Revista GeoPantanal, 10(18), 33-50.

Barrientos, P. (2015). Cuantificar la alteridad Recorridos, idas y vueltas durante la realización de la encuesta complementaria de pueblos indígenas (2004-2005) de la República Argentina. Tesis de maestría, dirigida por Gorosito Kramer, Ana María. Argentina

Bartolomé, M. A. (1997). Gente de costumbre y gente de razón: las identidades étnicas en México. Siglo XXI. México.

(2006). "Los laberintos de la identidad: procesos identitarios en las poblaciones indígenas"- Avá. Revista de Antropología, (9), 28-48. [fecha de Consulta 31 de Octubre de 2021]. Disponible en: https://www.redalyc.org/articulo.oa?id=169014140003

(2003). “Los pobladores del 'desierto'. Genocidio, etnocidio y etnogénesis en la Argentina"--Amérique Latine Histoire et Mémoire. Les Cahiers ALHIM. Les Cahiers ALHIM, (10). 
Bengoa, J. (2009). “¿Una segunda etapa de la Emergencia Indígena en América Latina?”Cuadernos de antropología Social, (29), 7-22.

Boixadós, R. (2012). "Dilemas y discursos sobre la continuidad de los pueblos de indios de la jurisdicción de La Rioja bajo las reformas borbónicas"-Mundo Agrario, 13(25).

Bonfil Batalla, G. (1972). "El concepto de indio en América"-Anales de Antropología, 9, pp. 43-89.

Bourdieu, P. (1993). "Génesis y estructura del campo burocrático"- Actes de la recherche en Sciences Sociales, 96, 97.

Bourdieu, P., \& Wacquant, L. (2005). Una invitación a la Sociología reflexiva. Buenos Aires: Siglo XXI

Briones, C. (2008). Diversidad cultural e interculturalidad: ¿de qué estamos hablando? En Hegemonía e interculturalidad. Poblaciones originarias y migrantes. La interculturalidad como uno de los desafíos del siglo XXI -C. García Vázquez (Comp) (pp. 35-58). Buenos Aires: Prometeo.

Carrasco, M. (2000). Los derechos de los pueblos indígenas en Argentina. Buenos Aires, IGWIA y Vinciguerra.

Carrasco, A. E., Sánchez, N. E. y Tamagno, L. (2012). Modelo agrícola e impacto socioambiental en la Argentina: monocultivo y agronegocios. La Plata: Serie Monográfica Sociedad y Ambiente: Reflexiones para una nueva América Latina. AUGM-Comité de Medio Ambiente.

Castelnuovo, N. (2019). "Representaciones e ideologías de ong confesionales en el Chaco Argentino”. Antropologías del Sur, 6(11), 39-61.

CEPAL, N. (2009). Censos 2010 y la inclusión del enfoque étnico: hacia una construcción participativa con pueblos indígenas y afrodescendientes de América Latina.

Colla, J. (2015). "Tensiones políticas y luchas campesinas originarias en la frontera con el capitalismo". In XI Jornadas de Sociología. Facultad de Ciencias Sociales, Universidad de Buenos Aires.

Del Popolo, F. (2008). Los pueblos indígenas y afrodescendientes en las fuentes de datos: experiencias en América Latina. Santiago de Chile: CEPAL.

Elichiry Nora (2009) Escuela y Aprendizajes. Trabajos de Psicología Educacional. Buenos Aires: Manantial (Capítulo 9).

Gordillo, G., \& Hirsch, S. (2010). "La presencia ausente: invisibilizaciones, políticas estatales y emergencias indígenas en la Argentina". En Movilizaciones indígenas e identidades en disputa en la Argentina (pp.15-38). Movilizaciones indígenas $e$ identidades en disputa en la Argentina. Buenos Aires: La Crujía. 
Guber, R. (2005). El salvaje metropolitano. Reconstrucción del conocimiento social en el trabajo de campo. Buenos Aires, Barcelona, México: PAIDÓS.

Guber, Rosana. 2011. La etnografía. Método, campo y reflexividad. Buenos Aires: Siglo XXI.

Instituto Nacional de Estadística y Censos República Argentina -INDEC-. (2015). "Base de datos REDATAM. Aspectos metodológicos" https://redatam.indec.gob.ar/argbin/RpWebEngine.exe/PortalAction?BASE=CPV2010B

(2015b). Cartilla sobre pueblos originarios. Censo nacional de población, hogares y familias 2010. https://www.indec.gob.ar/indec/web/Nivel4-Tema2-21-99

Iñigo Carrera, V. (2014). La medición estadística de población indígena en Argentina en perspectiva: del Censo Indígena Nacional de 1966-1968 a la Encuesta Complementaria de Pueblos Indígenas de 2004-2005. In XI Congreso Argentino de Antropología Social.

Katzer, L. (2019). "La etnografía como modo de producción de saber colaborativo. Reflexiones epistemológicas y metodológicas". En Perspectivas etnográficas contemporáneas en Argentina -L. Katzer \& Chiavazza, H. (Eds.) (pp. 49-85). Mendoza: Facultad de Filosofía y Letras de la Universidad Nacional de Cuyo.

Kramer, G. (2008). "Convenios y leyes: La retórica políticamente correcta del Estado"Cuadernos de Antropología Social, (28), pp. 51-65.

Lenton, D. (2010). "Política indigenista argentina: una construcción inconclusa"-Anuário antropológico, (I), 57-97.

Leone, M. (2016). "De "pueblo pobre" a "pueblo indígena". Pastoral aborigen y saberes antropológicos en la región chaqueña argentina (1979-1985)"- Quinto Sol, 20(3), 1-23.

Lorandi, A. M. (1988). El servicio personal como agente de desestructuración en el Tucumán Colonial -Revista Andina, 6(1), 135-173.

Maidana, C. A. (2019). "La necesidad de conocimiento y reconocimiento plural: Los pueblos indígenas en la provincia de Buenos Aires, Argentina"- Revista Antropologías del Sur, 6 (11), pp. 249 - 262.

Manzanelli, MDP (2021). "La distancia entre cuerpos reales y cuerpos imaginados. Marcas corporales/emocionales en dos comunidades diaguitas del Valle de Choromoro (Argentina)"- Boletín Sapiens Research, 1(1), 39-47.

(2021) "Lecturas del pasado en procesos contemporáneos de reafirmación comunitaria. El caso de la Comunidad Pueblo Tolombón (Valle de Choromoro, Argentina)"-

HiSTOReLo. Revista de Historia Regional y Local, 13 (26), 37-72. https://doi.org/10.15446/historelo.v13n26.85410 
Manzano, V. (2019). "La producción de la circularidad del conocimiento. Saberes, demandas y políticas de investigación". La política científica en disputa: diagnósticos y propuestas frente a su reorientación regresiva. La Plata: Universidad Nacional de La Plata. Facultad de Humanidades y Ciencias de la Educación.

Marradi, A. (1994). "Referenti, pensiero e linguaggio: una questione relevante per gli indicatori”"Sociologia e Ricerca Sociale XV, 43, 137-207.

Marradi, A., Archenti, N., \& Piovani, J. I. (2010). Metodología de las ciencias sociales. Argentina: Cengage Learning.

Mato, D. (2014). No "estudiar al subalterno", sino estudiar con grupos sociales "subalternos" o, al menos, estudiar articulaciones hegemónicas de poder-Desafíos, 26(1), 237-264.

Mignolo, W. D. (2007). "El pensamiento decolonial: desprendimiento y apertura. Un manifiesto". En El giro decolonial: reflexiones para una diversidad epistémica más allá del capitalismo global. -S. Castro-Gómez \& R. Grosfoguel (Comp.) (pp. 25-46). Bogotá: Siglo del Hombre Editores; Universidad Central, Instituto de Estudios Sociales Contemporáneos y Pontificia Universidad Javeriana, Instituto Pensar.

Míguez Palacio, R. M. (2021) "Reflexiones sobre la producción conjunta de conocimiento con pueblos indígenas"- $12^{\circ}$ Congreso Argentino De Antropología Social, Universidad Nacional de La Plata.

Naidorf, J., \& Perrotta, D. (2015). "La ciencia social politizada y móvil de una nueva agenda latinoamericana orientada a prioridades" -Revista de la educación superior, 44(174), 19-46.

Oliveira, L. R. C. D. (1992). Direitos humanos e cidadania no Brasil: algumas reflexões preliminares. Série Antropologia. Brasília, UnB.

Organización de Naciones Unidas -ONU-. (2014). Principios Fundamentales de las Estadísticas Oficiales.

Petz, I. (2008). CIDAC: notas disparadoras para pensarnos en nuestra praxis - Disponible en http://cidac.filo.uba.ar/revista/cidac-notas-disparadoras-para-pensarnos-en-nuestrapraxi s-1

Quijano, A. (2014). "Colonialidad del poder y Clasificación Social”. En Cuestiones y Horizontes. De la Dependencia Histórico-Estructural a la Colonialidad/Descolonialidad del Poder (pp. 285-327). Buenos Aires: CLACSO.

Ratier, H. (2010). "La antropología social argentina: su desarrollo"-Publicar en Antropología y Ciencias Sociales, IX: 17-47.

Tamagno, L., García, S. M., Caselli, M. A. I., del Carmen García, M., Maidana, C., Alaniz, M., y Paz, V. S. (2005). "Testigos y protagonistas: un proceso de construcción de 
conocimiento conjunto con vecinos Qom. Una forma de hacer investigación y extensión universitaria"-Revista Argentina de Sociología, 3(5), 206-222.

Trinchero, H. H. (2000). Los dominios del demonio. Civilización y barbarie en las fronteras de la Nación, el Chaco central. Buenos Aires: EUdeBA.

(2007). "Economía política de la exclusión. Para una crítica desde la experiencia de las empresas recuperadas por sus trabajadores (ERT)"- Cuadernos de antropología social, (26).https://doi.org/10.34096/cas.i26.4366

(2009). "Las masacres del olvido. Napalpí y Rincón Bomba en la genealogía del genocidio y el racismo de estado en la Argentina"-Runa, 30(1), 45-60.

(2010). "Los pueblos originarios en Argentina. Representaciones para una caracterización problemática”. Cultura y representaciones sociales, 4(8), 111-139.

Trinchero, H y Petz, I. (2014) "La cuestión de la territorialización en las dinámicas de integración universidad-sociedad: Aportes para un debate sobre el 'academicismo"'Papeles de Rrabajo, (27), 142-160. Disponible en: http://www.scielo.org.ar/scielo.php?script=sci_arttext\&pid=S1852-

45082014000100007\&lng=es\&nrm=iso. Acceso en: 11.11.18.

Valdivia Vargas, N. (2011). El uso de categorías etnico-raciales en censos y encuestas en el Perú: balance y aportes para una discusión. Lima:GRADE.

Vázquez, H. (2000). Procesos identitarios y exclusión sociocultural. La cuestión indígena en la Argentina. Buenos Aires: Biblos.

(2018). “Antropología Social y relaciones interétnicas" En Antropología Social: perspectivas y problemáticas-Juan Mauricio Renold (Coordinador) Tomo 1 Laborde Editor

Vázquez, H., Rodríguez, G., \& Bigot, M. (2001). "Derecho consuetudinario indígena y resistencia étnica"-Papeles de Trabajo, (9).

Zapata, L. (2014). "Ser y no ser indio/a Mapuche. Pueblo indígena y diseminación”. En Prácticas etnográficas. Ejercicios de reflexividad de antropólogas de campo -R. Guber (Comp.), (pp. 183-222). Buenos Aires: Miño y Dávila.

Fuentes

Abeledo, S; Acho, E.; Aljanati, L.; Aliata, S,; Aloi, J.; Alonso, M.; Altman, A.; Álvarez, M.; Aragon, G.; Ávalos, A.; Barandela, A.; Balazote, A.; Barbosa Becerra,J.; Benedetti, C.; Bensi, A.; Brac, M.; Brosky, J.; Brown, A.; Buttori, N.; Cantore, A.; Casimiro Córdoba, A.; Castellano, V.; Castelnuovo Biraben, N.; Castilla, M.; Castiñeira Alder, M.; Cherñavsky, S.; Colla, J.; Corvalán, E.; De Jong, I.; Delfino Edery, D.; Engelman, J.; Enriz, N.; Flores, M.; Flores Klarik, M.; Formia, M.; García Palacios, M.; García, J.; 
García, S.; Golé, C.; Gómez, S.; González, D.; Gualmes, M.; Guaquinchay, J.; Guiñazú, S.; Hecht, A.; Herrera, V.; Ifran, R.; Kantor, L.; Katzer, L.; Lacko, E.; Larsen, M.; Leavy, P.; Lenton, D.; Lodi, M.; López, A.; Luna Figueroa, L.; Lungui, J.; Maidana, C.; Mancinelli, G.; Martínez, A.; Martínez, Ma.; Medina, S.; Miguez Palacio, R.; Milana, P.; Minaverry, C.; Molina Pico, A.; Morey, E.; Murgida, A.; Nagy, M.; Naharro, N.; Padawer, A.; Pérez, M.; Petz, I.; Piaggi, L.; Quispe, L.; Radovich, J.; Real, A.; Reinoso, P.; Roda, L.; Rodríguez Celín, M.; Rodríguez Ramírez, S.; Romero, C.; Sabio Collado, M.; Schmidt, M.; Silva, S.; Stecher, G.; Szulc, A.; Tamagno, L.; Tello, R.; Tolosa, S.; Tomás, M.; Trinchero, H.; Valdata, M.; Valverde, S.; Vargas, E.; Varisco, S.; Vázquez, L.; Videla Manzo, M.; Voscoboinik, N.; Weiss, M. (2020). Informe ampliado: efectos socioeconómicos y culturales de la pandemia COVID-19 y del aislamiento social, preventivo y obligatorio en los Pueblos Indígenas en Argentina, Segunda etapa, junio 2020, http://antropologia.institutos.filo.uba.ar/sites/antropologia.institutos.filo.uba.ar/ files/info_covid_2daEtapa.pdf

Amnistía Internacional. (2021). Covid-19 y Derechos Humanos: La situación de la Provincia de Mendoza.

CELS; $\quad$ ODHPI; SERPAJ; GAJT; ANDHES;EPHADES;CTA;ENDEPA:MMP;ORCOPO;CJIRA;Comisión Provincial por la Memoria;FUNDAPAZ; Defensoría General de la Nación; CÁTEDRA LIBRE DE PUEBLOS ORIGINARIOS-UNPSJB; Comisión de Pueblos Originario e Inmigraciones de la Secretaría de Extensión de la Facultad de Trabajo Social de la UNLP Comisión de Derechos de los Pueblos Originarios y neoconstitucionalismo de la UBA Asociación de Abogados de Derechos Indígena (AADI) (2011). Informe sobre la situación de Los Pueblos Indígenas en Argentina: La Agenda Pendiente para el Relator De Pueblos Indígenas James Anaya (2011) https://www.cels.org.ar/common/documentos/InformeAnaya.pdf

ENDEPA. (2011). “Advertencia sobre la Inejecución de las Leyes Nacionales N²6.160 y N ${ }^{\circ} 26.554$ - Emergencia de la Posesión y Propiedad Comunitaria Indígena”

ENDEPA. (2018). “A Medias Tintas" Informe Temático Para La Incidencia Pública Estado De La Educación Intercultural Bilingüe en Argentina"

Ley $\mathrm{N}^{\mathrm{o}}$ 23.302. Ley sobre Política Indígena y apoyo a las Comunidades Aborígenes. Congreso Nacional argentino, Buenos Aires, Argentina, 30 de septiembre de 1985. http://servicios.infoleg.gob.ar/infolegInternet/anexos/20000-24999/23790/texact.htm

Ley 24.956. Incorpórase la temática de autoidentificación de identidad y pertenencia a comunidades aborígenes al Censo Nacional de Población y Vivienda del año 2000. Ciudad Autónoma de Buenos Aires, Argentina, 29 de abril de 1998.

Ley $\mathrm{N}^{\circ} 26.160$. Declárase la emergencia en materia de posesión y propiedad de las tierras que tradicionalmente ocupan las comunidades indígenas originarias del país, cuya personería jurídica haya sido inscripta en el Registro Nacional de Comunidades Indígenas u organismo provincial competente o aquéllas preexistentes. Ciudad Autónoma de Buenos Aires, Argentina, 1 de noviembre de 2006 
http://servicios.infoleg.gob.ar/infolegInternet/anexos/120000$\underline{124999 / 122499 / \text { norma.htm }}$

Red Agroforestal Chaco Argentina -REDAF- https://redaf.org.ar/observatorio/ 